Article

\title{
Spatio-Temporal Features of China's Urban Fires: An Investigation with Reference to Gross Domestic Product and Humidity
}

\section{Zhenbo Wang ${ }^{1,2}$, Xiaorui Zhang ${ }^{3, *}$ and Bo Xu ${ }^{4}$}

1 Key Laboratory of Regional Sustainable Development Modeling, Chinese Academy of Sciences, Beijing 100101, China; E-Mail: wangzb@igsnrr.ac.cn

2 Institute of Geographical Sciences and Natural Resources Research, Chinese Academy of Sciences, Beijing 100101, China

3 Department of Urban Planning, Hefei University of Technology, Hefei 230009, China

4 China Academy of Safety Science and Technology, Beijing 100012, China;

E-Mail:xub@cassp-pec.com

* Author to whom correspondence should be addressed; E-Mail: rgdhf@hfut.edu.cn; Tel.: +86-10-6488-8147; Fax: +86-10-6488-9301.

Academic Editor: Tan Yigitcanlar

Received: 30 April 2015 / Accepted: 8 July 2015 / Published: 22 July 2015

\begin{abstract}
Frequent fire accidents pose a serious threat to human life and property. The spatio-temporal features of China's urban fires, and their drivers should be investigated. Based on the Spatio-temporal Dynamic panel data Model (SDM), and using fire data gathered from 337 Chinese cities in 2000 to 2009, the influence of spatio-temporal factors on the frequency of urban fires was analyzed. The results show that (1) the overall fire incidence of China increased annually before 2002 and reduced significantly after 2003, and then high fire incidence increased in western China; (2) Spatio-temporal factors play a significant role in the frequency of Chinese urban fires; specifically, the fire assimilation effect, fire inertia effect and fire caution effect. The ratio of fire incidence of China has reduced significantly, and the focus of fire incidence moved towards the western region of China. GDP and humidity have a significant effect on urban fire situation change in China, and these effects may be referred to as "fire assimilation effects", "fire inertia effects" and "fire caution effects".
\end{abstract}


Keywords: urban fire; spatio-temporal features; SDM, humidity; GDP; the fire assimilation effect; fire inertia effect; fire caution effect

\section{Introduction}

The process of urbanization and industrialization has undergone rapid growth, leading to changes in fuel amounts, composition, and its configuration [1]. In addition to the change of land use and management activities, cities have become a highly-possible location for fire occurrence. According to statistics, on average more than 500 daily fire accidents occurred in China from 2000 to 2009. Frequent fire accidents pose a serious threat to human life and property. Fires can be classified into forest fires, grass fires, residential fires, building fires, industrial fires and mine fires based on the places where they occur. This paper focuses on the last four types listed above. The fuels, an ignition source, and sufficiently dry weather are the essential conditions of fire occurrence [2,3], whose relative importance at different scales can be difficult to quantify [4]. At landscape scale, the determinants are fuel, weather, human activities and topography [5-9]. At regional scale, climate variability and vegetation distribution are the more sensitive drivers of fire [10,11].

Urban areas belong to the landscape scale. Urban fire patterns are mainly influenced by the distribution of fuels, weather conditions (temperature and humidity) [12], and topography [13,14]. Human activities have a close relationship with the factors above. Humans can have both positive and negative effects on fire. Fuels provide the raw material acted on by fire. Cities are major spaces where substantial wealth is increasingly accumulated by rapid social and economic development [15]. On the one hand, with more and more fuels being used in urban construction and consumption of electricity and fire, there is a potentially high agglomeration of ignition source. On the other hand, social economic growth also promotes the development of firefighting facilities and flame retardant materials [16]. Higher human population density often increases ignition sources, whereas fire prevention activities tend to decrease fire occurrence [17,18]. All the factors abovementioned will undoubtedly impose significant influence on the occurrence of urban fires. Research analysis shows a significant relationship between the level of regional economic development and the rate of fire accidents However, different analysis result may be drawn from the variety of studies that have examined the economic development level. For example, Duncanson et al. found that fire accidents tended to decrease with increasing economic development [19]. The Australian research bureau of fire protection showed that an economic downturn coupled with imperfect firefighting equipment increased the fire risk [20]. In Smith et al.'s analysis, fire risk was shown to be relatively high in single-parent households and in households where the households members are unemployed, according to the research into fire accidents in Britain from 2002 to 2004 [21]. However, historical fire accident data in China before the year 2000 and after showed that the frequency of fires increases with economic development, except for Shanghai [22].

The relative importance of various drivers of fire activity can vary depending on the scale at which they are measured and the scale of analysis [23]. It is known that a warmer climate will increase fire activity at regional [24] to global scales [25]. At local scale, seasonality and meteorological conditions 
(temperature, humidity, wind speed and potential fuels) are more relevant. Material space morphology leads to microclimate change, evidenced by the heat island effect increasing the temperature and decreasing the humidity [26] of urban areas. Architectural form [27] in cities will also affect the local weather conditions in terms of wind orientation and speed. In the Western Amazon, drought intensity was the most important predictor of fire occurrence in local scale [24]. In Queensland, Australia, a high fire occurrence rate is related to high temperature [28]. Gunther found that, because there are few fixed heating systems in the rural parts of South America, the death rate from fires increased on cold days owing to the risks from using other types of heating [29]. Moreover, poverty makes this problem even worse. In the two largest cities in Indonesia — Jakarta and Surabaya - the number of fire accidents each month is affected by a change in climate, with fires occurring more frequently in the arid season; with, in Surabaya in particular, the number of fires decreasing with increasing humidity, while the number of fires increasing significantly when the humidity is less than $70 \%$ or when the rainfall measures less than $6 \mathrm{~mm}$ [30]. Similarly in China, a change in climate and humidity has a significant impact on the frequency of fires. Therefore, meteorological factors are closely related to fire occurrence. Climate and humidity have the largest influence on fire [31]. Specifically, a more arid climate increases the fire incidence rate while a more humid climate decreases the rate.

Climate change and socio-economic development have significant temporal and spatial characteristics; hence the incidence of fires is also associated with temporal and spatial characteristics $[12,14,32,33]$. Recent studies have focused on the spatio-temporal analysis of grassland and forest fires [34], and natural disasters [35]. A few researchers have tried to describe the geographical characteristics of urban fires. Jennings pointed out the geographical factors of fire accident analysis, and realized the spatial problems are related to fire accidents and the building environment. He argued that both the population and buildings are distributed along a certain density gradient; therefore, the rate of fire accidents is unevenly distributed [36]. Corcoran et al. analyzed the temporal and spatial change based on temporal and spatial exploratory analysis by using Queensland as an example [28]. Chang adopted the Spatial Lag Model (SLM) and the Spatial Error Correction Model (SEM) to analyze the relationship between the fire incidence rate and spatial factors, using Tainan City as an example [37].

In general, although progress has been made in related research on urban fires, there are still gaps. Firstly, the research above has examined either economic factors or climatic factors. However, urban fires are affected by both socio-economic and climatic factors, and the occurrence of fires seems to be random and uncertain. With rapid economic development and global climate change, academic research must take into consideration the compounding effects of both economic development and climate change on urban fire accidents. Secondly, most of the existing research on the influential effects of temporal and spatial factors on urban fires is based on exploratory analyses of some certain cities or regions, while little spatial econometric analysis has been carried out on the impact of large-scale temporal and spatial factors on urban fires. Thirdly, by using older data, the current situation regarding urban fires has not been addressed. In this study, we gathered urban fire accident data relating to China in the years 2000 to 2009, and used the Spatio-temporal Dynamic panel data Model (SDM) to demonstrate the effects of spatio-temporal factors on urban fire occurrences under the influence of rapid economic development and climate change. The fire accidents mentioned below all refer to urban fires. 
This paper identifies the fire incidence and its change to represent the fire situation and trend in different cities and regions. (Data set of climate data annual value from China Macao and Taiwan region are missing). The statist China Meteorological Administration website shows the average annual temperature and relative humidity from 2000 to 2009 from 188 meteorological stations. By Kriging interpolation, the raster maps of national annual average temperature and relative humidity are formed and then Zonal statistics available for each unit on the annual average relative humidity. The ArcGIS10.1 spatial analysis tools are utilized of Kriging interpolation and Zonal Statistics in this study. According to the common interpolation Kriging value, the average standard deviation of prediction result error of each year is less than 0.01 and the root-mean-square standard prediction deviation ranges between $1 \pm 0.1$.

\section{Study Area and Data}

The study is aimed at 337 Chinese prefecture-level (at least) administrative units (data of only Haikou and Sanya of Hainan province are presented but the data of Zhongwei of Ningxia province and Hong kong, Macao and Taiwan region are missing). The statistics on urban fires are obtained from Statistic Yearbook of Fire in China (2001 to 2010). The statistics on consensus and GDP per capita are derived from Statistic Yearbook of Regional Economy in China (2001 to 2010).

One of our objectives was to study the influence of economic development on the macro-statistical characteristics of the urban fire rate in China, with GDP per capita as the representative index. The change in GDP per capita reflects the basic macro-economic situation in one country or region and is highly related to education, investment, household income, etc. Existing research showed that climate and humidity had the largest influence [23,29-31], so we chose to principally study the influence of climate and humidity on urban fire, selecting average air temperature and humidity as the index of climate change. The number of fire accidents represents an important index which demonstrates severity. The occurrence index (the number of fire accidents among 1 million people) was chosen to represent the severity of fire occurrence in different areas and cities.

According to the "Meteorological annual data set from the China international exchange station ground", the grid's profile of national average air temperature and humidity could be generated through Kriging interpolation after capturing the annual average humidity in 188 meteorological stations from 2000 to 2009 . Furthermore, the annual average relative humidity per unit can be calculated by using zonal statistics. This paper adopts spatial analytical tools to perform Kriging interpolation and calculate zonal statistics. The standardized mean of interpolation result forecasting error is less than 0.01 and the root-mean-square standardized is $1 \pm 0.1$; therefore it is a precise method.

\section{Methods}

\subsection{Spatial Autocorrelation Model (Moran's I Model)}

Tobler (1970) put forward the First Law of Geography that any object is related to other objects with special consideration of distance, which shows the more closely located the objects, the stronger correlation exists between them [38]. It is called spatial autocorrelation which can be measured by Moran's I index. When the observation values are similar within a certain distance (d), the Moran's I is 
positive in significant level ( $p$-value less than 0.1 ), otherwise it is negative. If the observation values are arranged randomly, the Moran's I is zero. Moran's I can be classified into Global Moran's I (GMI) and Locan Moran's I (LMI). GMI is used to judge the spatial agglomeration degree of China's urban fires, and LMI is used to explore the spatial distribution of the "hot spots" and "cold spots". Due to the possible local spatial autocorrelation observations existing in the overall spatial random sample distribution, GMI and LMI are both applied in this paper to analyze the agglomeration features of the urban fires. GMI refers to:

$$
I=\frac{n}{S_{0}} \frac{\sum_{i=1}^{n} \sum_{j=1}^{n} w_{i j}\left(\mathrm{x}_{i}-\bar{x}\right)\left(\mathrm{x}_{j}-\bar{x}\right) z_{j}}{\sum_{i=1}^{n}\left(\mathrm{x}_{i}-\bar{x}\right)^{2}}
$$

in which $n$ is the total number of the sample, $w_{i j}$ is spatial weight matrix $(n \times n), x_{i}$ and $x_{j}$ are respectively the fire occurrence rates in places of $i$ and $j . \bar{x}$ is the average value, and $S_{o}$ is the sum of all its elements. LMI is defined as:

$$
I_{i}=\sum w_{i j} Z_{i} Z_{j}
$$

in which $Z_{i}$ and $Z_{j}$ are the standardized values of fire occurrence rate. When $I_{i}$ and $Z_{i}$ are both positive at a significant level ( $p$-value less than 0.05), it means that the fire occurrence rate in place $i$ and the units nearby are high. It is termed as High Concentration Area $(\mathrm{HH})$; by contrast, while $I_{i}$ and $Z_{i}$ are negative, it shows that the fire occurrence rate in place $i$ and its neighboring units are low which are called Low Concentration Area (LL). If $I_{i}$ is positive and $Z_{i}$ is negative, it means that the fire occurrence rate of place $i$ is higher than that of the neighboring units, which are referred to High Low Concentration Area (HL). While if $I_{i}$ is negative and $Z_{i}$ is positive, the fire occurrence rate of place $i$ is lower than that of the units nearby, which are termed as Low High Concentration Area (LH).

\subsection{Selecting Incident-Inducing Factors of Fire Accidents}

The starting point in the Granger causality test of judgment was to examine whether the prophase information of X contributed to the decrease of MSE (Mean Square Error) of Y [39]. Moreover, this paper compared the MSE value with that when not using prophase information of $\mathrm{X}$. If there is no change in MSE value, $\mathrm{X}$ has no influence on $\mathrm{Y}$ under the Granger causality test, or " $\mathrm{Y}$ is not caused by $\mathrm{X}$ Granger". On the contrary, there is causality under Granger, or " $\mathrm{X}$ is the Granger reason of Y". Gao describes specific methods [40].

The annual average temperature and average relative humidity between the years 2000 and 2009 were recorded based on those of 188 China International Exchange Ground Stations (Figure 1). 


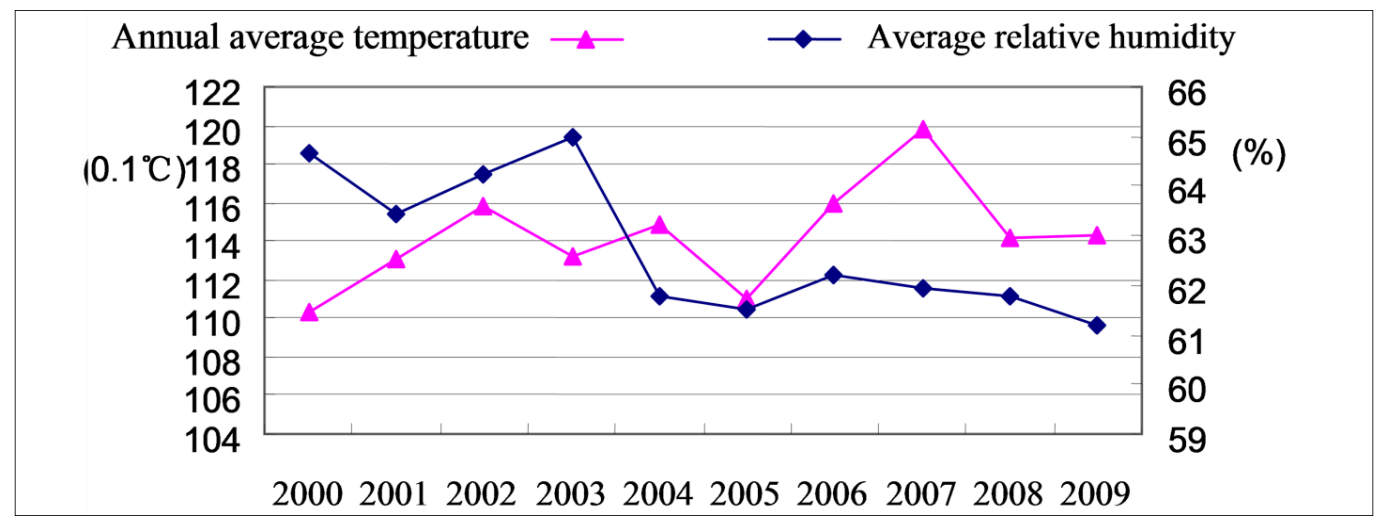

Figure 1. Annual average temperature and annual average relative humidity of China, 2000 to 2009.

Assuming all the disaster-inducing factors (GDP per capita, annual average relative humidity, annual average temperature) are not the Granger cause of the fire occurrence situation, the Granger causality test examines whether the chosen disaster-inducing factors really cause the change in fire occurrence (Table 1).

Table 1. Granger causality test results of fire rate and other factors of China.

\begin{tabular}{ccccc}
\hline Lags & Null Hypotheses & F Stat. & Prob. & Conclusions \\
\hline \multirow{3}{*}{1} & $H$ is not the Granger cause of $F$ & 9.42 & 0.01 & rejected \\
& $T$ is not the Granger cause of $F$ & 0.73 & 0.41 & accepted \\
& $G$ is not the Granger cause of $F$ & 9.45 & 0.00 & rejected \\
\hline \multirow{2}{*}{2} & $H$ is not the Granger cause of $F$ & 2.39 & 0.16 & accepted \\
& $T$ is not the Granger cause of $F$ & 0.73 & 0.52 & accepted \\
& $G$ is not the Granger cause of $F$ & 2.57 & 0.15 & accepted \\
\hline
\end{tabular}

Note: $H, T, G, F$ represent the logarithmic values of the annual average relative humidity, annual average temperature, GDP per capita, and fire rate, respectively.

When the lag is $1, \mathrm{H}$ and $\mathrm{G}$ are both the Granger cause of $\mathrm{F}$, but $\mathrm{T}$ is not the Granger cause of $\mathrm{F}$; when the lag is $2, \mathrm{H}, \mathrm{T}$ and $\mathrm{G}$ are not the Granger cause of $\mathrm{F}$. This means that the annual average relative humidity and GDP per capita are the Granger causes of fire rate; moreover, they also have a significant influence on the fire rate one year later. However, the annual average temperature does not significantly influence the fire rate. Therefore, the annual average relative humidity and GDP per capita can be considered to be incident-inducing factors. This paper only considers annual average relative humidity as the characteristic factor of climate change, and uses GDP per capita to represent economic development and the fire occurrence rate to represent the change in urban fires.

\subsection{Fire-GDP-Humidity Model (FGHM)}

C.W. Cobb and Paul H. Douglas put forward the Cobb-Douglas production function in the 1930s [39]. Labor $\mathrm{L}$ and investment $\mathrm{K}$ are explanatory variables, $\mathrm{Y}$ is the output, and the model is shown below:

$$
Y=A K^{\alpha} L^{\beta} e^{u}
$$

As mentioned in Section 3.2, the fire situation and trend has a strong correlation with GDP and humidity. Assuming GDP per capita and annual average relative humidity as inputs, and fire 
occurrence rate as output, according to the Cobb-Douglas production function, the fire input-output model is:

$$
F=A G^{\beta} H^{\gamma} e^{u}
$$

where $G$ is GDP per capita, $H$ is annual average relative humidity, $F$ is fire occurrence rate, $\beta, \gamma$ are the elasticity of the economic and climate factors.

This model is based on the panel data model through logarithmic transformation:

$$
\ln \left(F_{i t}\right)=\alpha+\alpha_{i}+\beta \ln \left(G_{i t}\right)+\gamma \ln \left(H_{i t}\right)+u_{i t}
$$

where $\alpha$ is the average intercept value of each section, $\alpha_{i}$ is the deviation value that each section deviates from the average $\alpha, \mu_{i}$ is the residual value of each section, $F_{i t}$ is the fire occurrence rate of unit $i$ in the $t$ phase, $G_{i t}$ is GDP per capita (thousand yuan) of unit $i$ in the $t$ phase, $H_{i t}$ is the annual average humidity of unit $i$ in the $t$ phase.

\subsection{Co-Integration Test of Each Index in FGHM}

In order to avoid spurious regression [40], we used the co-integration test of $\ln (F), \ln (G)$ and $\ln (H)$.

The Pedroni (Engle-Granger based) method, Kao (Engle-Granger based) method and Fisher (combined Johansen) method were used to perform the test. The trace test and Max-Eigen test both rejected the null hypothesis at a $1 \%$ significance level. There is a co-integration relationship among the variables and there are three co-integration vectors.

After examining the above three test methods, the results show a co-integration relationship among $\ln (F), \ln (G)$, and $\ln (H)$. There is a long-term equilibrium relationship among economic development, climate change and fire situation change in urban China between 2000 and 2009. In the short term, the fire situation may deviate from average value, and it will return to the equilibrium situation determined by the economic development level and climate situation as time goes by. Therefore, it is feasible to build a regression function based on the three variables and the FGHM model is efficient.

\subsection{The Fire-Space Dynamic Model}

The autocorrelation of a temporal series must be considered when analyzing natural environment and socio-economic problems. The values before and after some points are correlated, which reflects the regularity of temporal series. The spatial panel data model combines both the cross-section and time series panel data. This model is widely used because it takes into consideration both variables' regional difference and time influence and avoids the multi-collinearity towing to the missing independent variables. The SDM is one of the spatial panel data models that has been developed recently, and it can reflect the dynamic change of research sample both in space and time. It not only considers the spatial lag of explained variables, but also considers the time lag and spatial time united lag. Thus, this model has more explanatory strength [41].

The basic form of SDM is as follows:

$$
Y_{n t}=\lambda_{0} W_{n} Y_{n t}+\gamma_{0} Y_{n, t-p}+\varphi_{0} W_{n} Y_{n, t-p}+X_{n t} \beta_{n}+c_{n}+\varepsilon_{n}
$$


where $Y_{n}$ is the dependent variable, $X_{n}, \beta_{n}$ is the cross-section explanatory variable k-dimensional vector and k-dimensional parameter corresponding to $i=1,2, \ldots, \mathrm{N} . \mathrm{W}_{\mathrm{n}}$ is the spatial weight matrix, $\mathrm{c}_{\mathrm{n}}$ is the intercept, $\varepsilon_{n}$ is the random error vector, $Y_{n, t-p}$ is the time lag p-order time lag, $\lambda_{0}, \gamma_{0}, \varphi_{0}$ is the parameter of spatial lag, time lag and spatial and time united lag.

The FGHM does not consider the spatial correlation of the fire situation. The fire occurrence rate of cities tended to increase from 2000 to 2002 and started to decline from 2002 to 2009 . The same trend is reflected from the autocorrelation Moran index (Figure 2). Each year's Z(I) value is larger than 1.96 and illustrates the significant autocorrelation of the fire occurrence rate each year. The fire occurrence rate in mainland China has significant spatial accumulative features. Regions with a high fire occurrence rate are located near regions with a high fire occurrence rate; similarly, regions with a low fire occurrence rate are located near areas with a low fire occurrence rate.

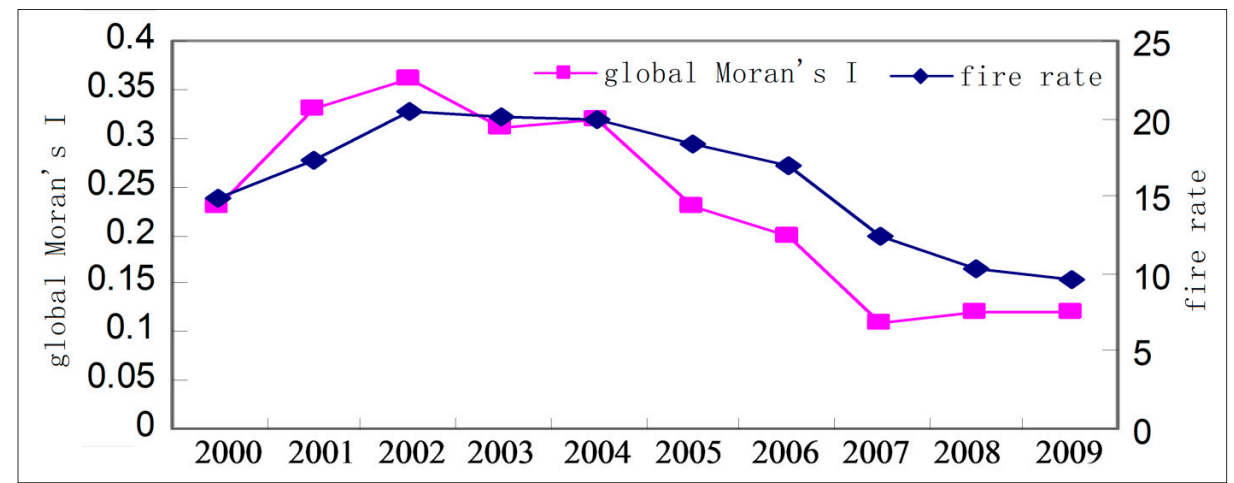

Figure 2. Fire rate and global Moran Index from 2000 to 2009.

Given that the fire distribution has spatial accumulative features, the spatial autocorrelation of fire should be considered in the analysis. The effect of spatial factors on the change in the fire occurrence rate is very important because there are imitative, competitive and cooperative behaviors in terms of the productive level, living standard and fire safety management of the surrounding regions. Moreover, the fire analysis should also consider the dynamic effect of time considering that the fire situation change is continuous and gradual. Therefore, the fire SDM (FSDM) is constructed after an extension of the FGHM based on the SDM:

$$
\ln \left(F_{i t}\right)=\alpha+\alpha_{i}+\beta_{1} \ln \left(G_{i t}\right)+\beta_{2} \ln \left(H_{i t}\right)+\beta_{3} \ln \left(\left(I_{t} \otimes W_{N}\right) F_{i t}\right)+\beta_{4} \ln \left(F_{i, t-1}\right)+\beta_{5} \ln \left(\left(I_{t} \otimes W_{N}\right) F_{i, t-1}\right)+\mu_{i}
$$

where $\alpha$ is the average intercept value of each section, $\alpha_{i}$ is the deviation value between the intercept of each section and average value of $\alpha . \mu_{\mathrm{i}}$ is the residual value of each section, $F_{\text {it }}$ is the fire occurrence rate of section $i$ of the $t$ phase (number/ million people), Git is the GDP per capita (thousand yuan) of section $i$ of the $t$ phase, $\mathrm{H}_{\mathrm{it}}$ is the annual relative humidity(\%), $\mathrm{I}_{\mathrm{t}}$ is the unit matrix, $\mathrm{W}_{\mathrm{N}}$ is the spatial weight matrix, $\beta_{1}, \beta_{2}, \beta_{3}, \beta_{4}, \beta_{5}$ is the spatial lag parameter, time lag parameter, spatial and time united lag parameter of the fire occurrence rate.

If adopting the spatial weight based on adjacency relation, the spatial lag variable is the average value of $\mathrm{K}$ surrounding regions, that is $F_{i t}{ }^{\prime}=\left(I_{t} \otimes W_{N}\right) F_{i t}=\frac{1}{k} \sum_{i=1}^{k} F_{i t}, F_{i t}{ }^{\prime}$ is the average fire occurrence 
value of $\mathrm{K}$ surrounding areas in unit $i$ of the $t$ phase. Then FSDM can be simplified as follows:

$$
\ln \left(F_{i t}\right)=\alpha+\alpha_{i}+\beta_{1} \ln \left(G_{i t}\right)+\beta_{2} \ln \left(H_{i t}\right)+\beta_{3} \ln \left(F_{i t}{ }^{\prime}\right)+\beta_{4} \ln \left(F_{i, t-1}\right)+\beta_{5} \ln \left(F_{i, t-1}{ }^{\prime}\right)+\mu_{i}
$$

where $F_{i t}{ }^{\prime}$ represents the 1-order spatial lag parameter of the fire occurrence rate, $F_{i, t-1}$ is the 1-order time lag parameter of the fire occurrence rate, $F_{i, t-1}$ ' refers to the 1-order time and spatial unit lag parameter of the fire occurrence rate.

The FSDM is as follows based on the estimation of EVIEWS6.0:

$$
\ln \left(F_{i t}\right)=4.63+\alpha_{i}-0.15 \ln \left(G_{i t}\right)-0.99 \ln \left(H_{i t}\right)+0.57 \ln \left(F_{i t}{ }^{\prime}\right)++0.54 \ln \left(F_{i, t-1}\right)-0.20 \ln \left(F_{i, t-1}{ }^{\prime}\right)+\mu_{i}
$$

The fit of the model is good. All the parameters pass the $1 \%$ significance level test. The goodness of fit of this model is 0.94 . The adjusted RR reaches to 0.93 and natural logarithm of the likelihood value is -4545.30 . All these values illustrate that the model has a high degree of fitting.

\section{Result Analysis}

\subsection{The Spatio-Temporal Features of China Fires}

In Equation (1), the GMI result of urban fires each year indicated by Figure 2 shows that Z(I) is more than 1.96 each year. Residuals are examined by spatial autocorrelation, achieving the significant result of their Moran's I less than 0.05 in average in 2003, 2004 and 2009 while insignificant during other years by contrast [42-44]. It illustrates the significant autocorrelation of the fire occurrence rate each year.

Table 2. The statistical tests of the post-fit residuals.

\begin{tabular}{cccccccccc}
\hline & 2001 & 2002 & 2003 & 2004 & 2005 & 2006 & 2007 & 2008 & 2009 \\
\hline Moran'I & -0.02 & 0 & 0.07 & 0.03 & 0 & -0.01 & -0.02 & -0.01 & -0.04 \\
$\mathrm{Z}$ & -1.44 & 0.17 & $4.99 * *$ & $2.32 *$ & 0.47 & -0.58 & -0.97 & -0.2 & $-2.38 *$ \\
\hline \multicolumn{7}{c}{$*$ and ** represent significant difference at a level of 0.05 and 0.01 , respectively. }
\end{tabular}

GIM increased from 0.23 to 0.36 from 2000 to 2002, which represents the higher level of spatial agglomeration of China fires occurrence rate. The following decreasing trend shows the lower level of its spatial agglomeration, taking on the dispersion trend instead. The trend of fire spatial agglomeration is consistent with that of the overall fire occurrence rate of China (Figure 2). Since then governments of all levels have enhanced the fire safety management and its investment, thus decreasing the fire occurrence rate.

LMI index in Equation (2) indicates the fire agglomeration features of some local areas (seen in Figure 3). There are significant fire spatial agglomeration phenomenon in local China. Each year the $\mathrm{HH}$ units are mainly distributed in northeast, central-north part and Xinjiang province of China. In early periods, they also gather in Bohai Rim and Yantze River Delta, which are the important areas for fire prevention and protection. LL units mainly spread in southwest part of China with low level of fire occurrence rate due to the local warm and humid climate yet underdeveloped economy. As for LH and HL units, the spatial correlation is not that obvious with little distribution for each year. Table 3 shows the number of cities for each type of area. During the period from 2000 to 2009, the number of HH 
units gradually declined year by year. The urban spatial agglomeration of high fire occurrence rate has become weaker and tended to be randomly distributed with decentralization. LL units experienced oscillating declines in amount and totally disappeared after 2007. The spatial agglomeration of low fire occurrence rate took on a random and dispersed distribution. After 2007, the adoption of a related national policy contributed to the constant decreasing fire occurrence rate, evidenced by the following regulations. In 2006, the State Council issued The State Council Opinion on Further Strengthening.

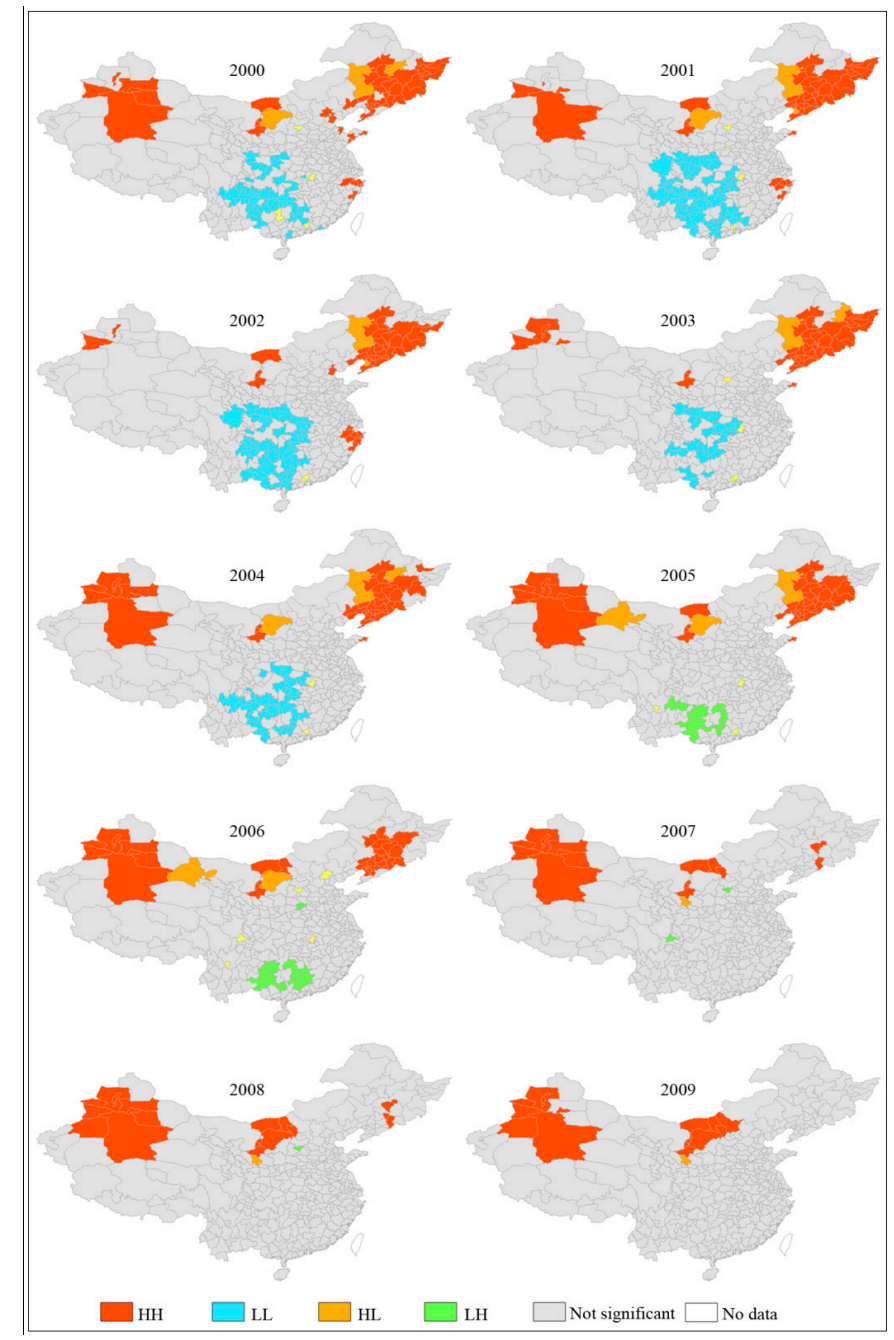

Figure 3. The analysis result on fire occurrence rate local autocorrelation of 2000 to 2009.

The Work of Fire (Guo Fa [2006] No.15), depending on which governments of all levels and public security fire departments launched a nationwide investigation and remediation of fire hazards, further enhancing the fire supervision and management. The Ministry of Public Security, the National Development and Reform Commission and the Ministry of Finance jointly issued the "The 3rd-Phase Promotion Planning of Fire Fighting Equipment" on 29 May 2007, in which a decision was made that from 2007 to 2010, with the total investment of 931.3 million yuan mainly subsidized by central government and partially supported by local government, 120 public security fire secret squadrons would be established in China's main cities and areas, gradually improving the fire aid system and enhancing the capacity to withstand major disasters and accidents. All these measures have effectively curbed the fire occurrence, providing guarantee for social steady and harmonious development. 
Table 3. The units number of each type of local autocorrelation, 2000 to 2009.

\begin{tabular}{ccccc}
\hline Year & HH & HL & LH & LL \\
\hline 2000 & 47 & 6 & 4 & 33 \\
2001 & 43 & 5 & 4 & 52 \\
2002 & 43 & 3 & 3 & 49 \\
2003 & 40 & 7 & 3 & 24 \\
2004 & 40 & 4 & 4 & 32 \\
2005 & 41 & 7 & 4 & 13 \\
2006 & 35 & 8 & 2 & 15 \\
2007 & 18 & 5 & 1 & 0 \\
2008 & 21 & 3 & 1 & 0 \\
2009 & 17 & 2 & 1 & 0 \\
\hline
\end{tabular}

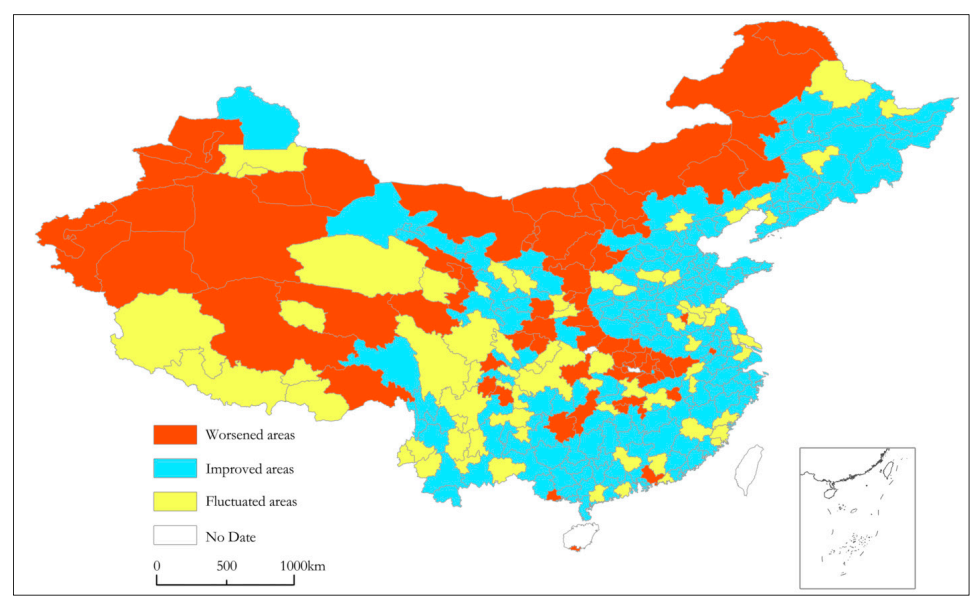

Figure 4. The classification of fire occurrence rate time series trend.

To apply the method of "Three Points Moving Average Algorithm" in calculating the correlation coefficient Pearson $(r, t)$ from 2000 to 2009, of which $r$ refers to the fire change rate and $t$ for time. The result that Pearson $(r, t)$ less than -0.5 represents the negative correlation between $t$ and $r$, i.e., the fire occurrence rate taking on the declining trend with the time passing by; by contrast, if Pearson $(r, t)$ is over 0.5 , the correlation between $t$ and $r$ is positive, which means the fire occurrence rate is increasing year by year. As for the units, we use $t$ as the independent variable and $r$ as the dependent variable to calculate the slope $(r, t)$, which reflects the degree or speed of $r$. According to the calculation results, the cities around the nation can be classified into three types: $\operatorname{Improved}$ areas: $\operatorname{Pearson}(r, t)<-0.5$, decreasing fire occurrence rate. The higher $\operatorname{slope}(r, t)$ absolute value shows the accelerated improvement trend; Worsened areas: Pearson $(r, t)>0.5$, increasing fire occurrence rate. The higher slope $(r, t)$ absolute value means the faster deterioration trend; Fluctuated areas: $-0.5 \leq$ Pearson $(r, t) \leq 0.5$, fluctuations or no significant features in fire occurrence rates (Figure 4).

There are in total 186 cities with improved areas, mainly distributed in the northeast, northern, eastern, southern part of China. In recent years, the fire occurrence rate has gradually declined, especially in northeast China. The area has a relatively developed economy and has achieved remarkable results in fire disaster prevention and reduction within the sound development cycle. 
There are in all 74 cities that have worsened areas, mainly distributed in the west of HeiheTengchong Line, as well as Shaanxi and Hubei provinces. The urban fire occurrence rate increased relatively quickly influenced by development. Economic development has been promoted later in this area, however, fire safety has not developed at the same rate, thus leading to the higher fire occurrence rate.

There are 77 cities in total in the fluctuation area, distributed in southwest China. The area can be described in terms of the following three situations: firstly, the fire occurrence rate initially trended upwards and then downwards, i.e., the fire occurrence rate worsened during the early stages and then improved more recently; secondly, the fire occurrence rate declined at first and then increased, i.e., the fire occurrence rate demonstrated a sound trend but later worsened; thirdly, the fire occurrence rate continually fluctuated. These units are expected to further enhance fire supervision and management in the future to prevent a worsening trend and are expected to achieve gradual improvements.

\subsection{The Influence of GDP and Humidity}

The distribution of the average fire rate from 2000 to 2009 is shown in Figure 2. The urban fire occurrence rate distribution in China shows a high occurrence rate in the north and a low rate in the south; the eastern area also has a higher occurrence rate than the western area (Figure 5a). This is in accordance with the regional climate conditions and the regional economic development level on a whole. In China, the southern area is warm and wet while the northern area is cold and dry (Figure 5c,d). The eastern area is well developed and the western area is less developed (Figure 5b).

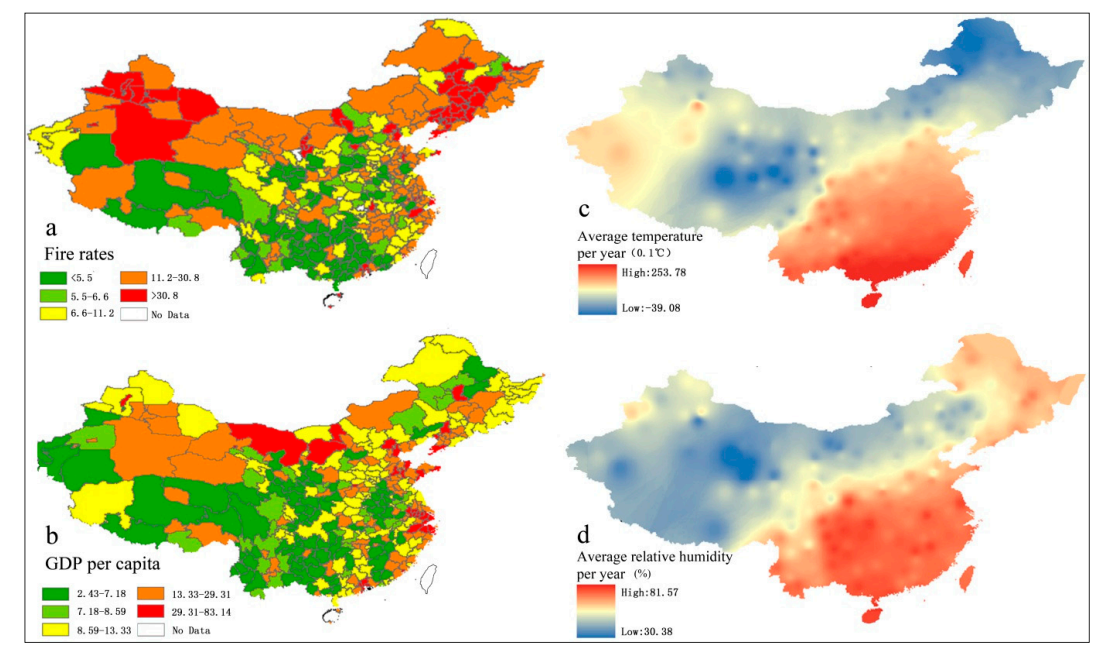

Figure 5. The average fire rate, temperature, GDP per capita and relative humidity of China, 2000 to 2009.

(1) The influence of GDP on the fire situation. The parameter of economic factor $\left(\beta_{1}\right)$ is negative. This indicates that economic development helped to improve the fire situation in general. This is consistent with research from other countries. However, we obtained different results after analysis because we chose data from the late 1990s to early 2000. During this important period of economic transformation, there was a lack of firefighting investment in each city. The cost of firefighting equipment was very high and the numbers of those fighting the fires was relatively small. The fire safety level and ability to respond to emergencies was affected by a lack of public firefighting 
facilities. Therefore, the fire risk and fire occurrence rate increased prior to 2002. After 2003, all levels of government increased their fire safety management, investment and prevention, and strengthened their fire response capability. The fire occurrence rate decreased with rapid economic development. From 2000 to 2009, economic development reduced the fire occurrence rate. A 1\% increase in GDP per capita led to a $0.15 \%$ decrease in the annual average fire occurrence rate.

On the one hand, according to our analysis results, economic development led to an increase in fire occurrences, and the accumulation of people and goods associated with economic development increased the likelihood of fire accidents. This is not good for fire prevention and control. On the other hand, our results showed that economic development also has an inhibitory effect on fire occurrences as economic growth can increase fire safety investment and strengthen fire prevention and control, and improve fire safety at a management level. Therefore, economic development has a dual effect on the fire situation. There are different results for different economic development periods in different regions; this has been illustrated by a historical analysis undertaken by Liang and Ren [45]. The Chinese government first introduced the "Fire Statistic Management Rule" (implemented in 1990) in 1989, and this ruling was revised in 1996 (implemented in 1997); this explains the statistical standard change during this period and why the fire occurrence rate fluctuated sharply between 1990 and 1997 , as shown in Figure 6.

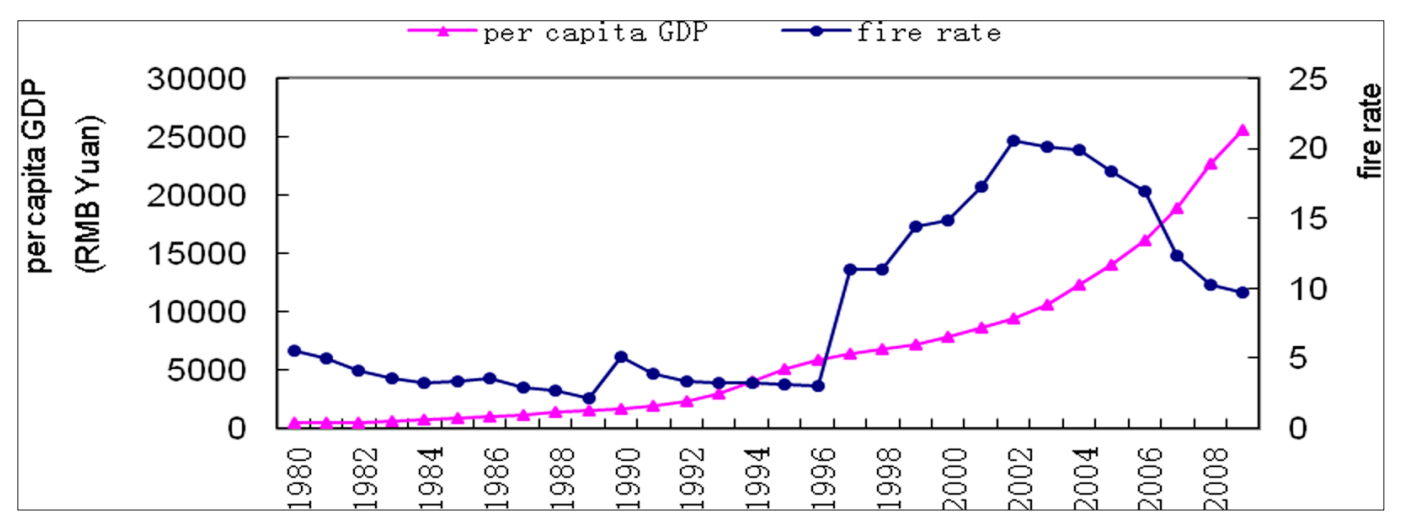

Figure 6. Per capita GDP and fire rate of China, 1980 to 2009.

(2) The influence of humidity change on fire situation change. The "National Climate Change Assessment Report I: the History and Future Trend of Chinese Climate Change" pointed out that China has the same pattern of climate change as other regions in the world, and, on average, the climate is warmer and drier than that in Northern hemisphere regions or other parts of the world [46]. $\mathrm{Xu}$ et al. proposed that there will be a visible warming/drying pattern in most Chinese regions in the future (2011 to 2080) [47]. Figure 4 also illustrates the significantly arid climate in 2000 and 2009.

The parameter of the climate factor $\left(\beta_{2}\right)$ in the FSDM is negative; this means that a drier climate has a negative effect on the fire situation. Because combustible matter exists in the atmosphere, it exchanges energy and material and keeps in water equilibrium with the surrounding environment. When a combustible is burned, the water will first parch and then evaporate and decompose into combustible gas. Therefore, the drier the climate, the lower the water content, as well the lower the fire-burning energy, or latent heat of evaporation, the higher the fire risk. Considering only the effect 
of the humidity factor on fire, a $1 \%$ decrease in the annual average relative humidity can lead to a $0.99 \%$ increase in the national average fire occurrence rate.

Figure 4 shows the decreasing trend of the overall fire occurrence rate in China; the change in rate was the combined result of economic development and climate change. Although the warming/drying trend in China had a negative effect on the fire situation, economic growth reversed this trend and improved the overall fire situation in China after 2003. Given that the sensitivity $\left(\beta_{2}=0.99\right)$ of the fire occurrence rate to the annual average relative humidity change was greater than that of the GDP $\left(\beta_{1}=0.15\right)$, the Chinese government has made progress in facing the challenge of the negative effect of climate change on urban fires. As the climate becomes drier, the fire prevention and control challenge becomes much greater. Therefore, it is necessary to increase the investment in fire safety and prepare a contingency plan in order to reduce the fire occurrence rate.

\subsection{The Spatio-Temporal Regulation of China's Urban Fires}

(1) Fire assimilation effect. The fire assimilation effect refers to the process whereby people's attitude and behavior gradually moves toward the attitude and behavior of a reference population or people. It is an unconscious adjustment of individuals, who are imperceptibly influenced by the outside environment. In neighboring cities, people have similar living habits and the fire risk situation is broadly similar. There may be comparative and imitative behavior patterns that should be considered when managing and investing in fire safety. The fire situation in one region is affected by that in the neighboring region. This is called the "fire assimilation effect". The spatial lag parameter $\left(\beta_{3}\right)$ in the FSDM can be viewed as the fire assimilation effect; the larger the absolute value of $\beta_{3}$, the stronger the fire assimilation effect, and vice versa.

The spatial lag parameter $\left(\beta_{3}\right)$ is positive and significant at a $99 \%$ confidence interval. This means that the fire situation has a significant assimilation effect. The fire situation in certain regions is not only affected by factors in these particular regions by self-factors, but also influenced by the fire situation in neighboring regions. An improvement or deterioration in the fire situation can lead to an improvement or deterioration in neighboring regions. The estimated value of the spatial lag parameter $\left(\beta_{3}\right)$ is 0.57 ; this means that a $1 \%$ increase in the fire occurrence rate in neighboring regions will lead to a $0.57 \%$ increase in the occurrence rate for local region.

This result suggests that, owing to the fire assimilation effect, there needs to be improved cooperation between regions in order to reduce the rate of fire occurrences. Fire safety administration departments should take joint actions and communicate with each other regarding decisions about policies, planning, the provision of equipment, and the management and supervision of the firefighting itself. All such departments are encouraged to learn from and compete with each other in order to improve the level of fire safety. Furthermore, the department in charge can provide demonstrations on fire disaster prevention and control that encourage surrounding regions to improve their own levels of fire safety.

(2) Fire inertia effect. Plenty of economic magnitudes experience economic behavior inertia in socio-economic activities. Research shows that the fire system is linked to previous events in history and fire disasters have a structural continuity from the past to the present and from the present to the future [48]. This is called "fire inertia". The fire inertia effect refers to the fire situation trend of being 
consistent with the previous change trend, and there is a logical relationship between the fire situation at one time point and the fire situation at an earlier time point. The fire situation and its change experience inertia in two surrounding areas on account of similar living habits, fire safety management measures and socio-economic production behavior. Therefore, regions where fire accidents occur frequently in an earlier period will be most likely to suffer a fire accident in the future. Regions where the fire situation is improved in the early days will continue to improve in the future. The time lag parameter $\left(\beta_{4}\right)$ in the FSDM represents the fire inertia effect. The larger the absolute value of $\beta_{4}$, the larger the fire inertia effect, and vice versa.

The time lag parameter $\left(\beta_{4}\right)$ is positive and significant at a $99 \%$ confidence interval. This means that the fire inertia effect is significant based on fire disaster data in China. The estimated value of the time lag parameter $\left(\beta_{4}\right)$ is 0.54 , which indicates that a $1 \%$ decrease in the previous fire occurrence rate will lead to a $0.54 \%$ decrease in the current fire occurrence rate. The parameter of the fire inertia effect $\left(\beta_{4}=0.54\right)$ and the assimilation effect $\left(\beta_{3}=0.57\right)$ are roughly the same and reflect the similar positive effect of both the internal (fire inertia effect) and external (fire assimilation effect) factors on the fire situation in one region.

This result suggests that the fire inertia effect should be fully utilized. Specifically, for regions that have a fire deterioration trend, the relevant departments should increase the safety investment in large fire prevention and control and also strengthen the management of fire safety in order to eliminate the fire inertia effect; these actions would help to reverse the fire deterioration trend. In those areas where the fire situation is improving gradually, the relevant departments should continue their current fire safety management and continue to invest in fire safety activities. They, too, should use the fire inertia effect to further improve the fire situation. Nowadays, the fire situation is improving gradually in China's eastern areas. However, the middle and western regions still have terrible fire situations resulting from poor economic development and a low level of firefighting investment. Relevant departments should publicize their effective practical experiences to the middle and western regions and increase their firefighting investment in order to reduce the fire inertia effect.

(3) Fire caution effect. Previous cases of fire in one area will alarm surrounding areas, and the administrative department tends to prevent any similar incidents by engaging in a safety investigation and examining fire risks. These measures decrease the fire risk; this is called the "fire caution effect". The spatial and time-united lag parameter $\left(\beta_{5}\right)$ in the FSDM illustrates this effect; the larger the absolute value of $\beta 5$, the more significant the fire caution effect, and vice versa.

The spatial and time-united lag parameter $\left(\beta_{5}\right)$ is negative and significant at a $99 \%$ confidence interval; this illustrates that fire accidents in China have a significant caution effect. Previous fire accidents in one region will alarm the surrounding area and reduce the fire occurrence rate in the surrounding area. A $1 \%$ increase in previous fire accidents in one area will cause a $0.20 \%$ decrease in fire accidents in the surrounding region. This result suggests that related departments can learn from fire accidents in the surrounding area, and can investigate and eliminate fire risk based on the fire caution effect.

There are differences and connections between the fire caution effect and the fire assimilation effect. The fire assimilation effect analyzes the spatial section at a specific time point and reflects the fire spatial autocorrelation; the fire inertia effect analyzes the time series of fire and demonstrates the 
time connection in some regions; the fire caution effect combines the assimilation effect and the inertia effect and analyzes the time series as well as the spatial section.

However, the fire caution effect is only a remedial strategy because the parameter of this effect $\left(\beta_{5}=-0.20\right)$ is obviously lower than that of the fire assimilation $\left(\beta_{3}=0.57\right)$ and inertia effects $\left(\beta_{4}=0.54\right)$. Therefore, strengthening the management of fire safety and regional cooperation are key points in improving the fire situation.

\section{Conclusions and Discussion}

Fire situation change results from a combination of economic development and climate change. The response sensitivity of fire situations to climate change is higher than the sensitivity to economic development. A $1 \%$ increase in GDP per capita will lead to a $0.15 \%$ decrease in the average fire occurrence rate in China; however, a $1 \%$ decrease in the annual average humidity will lead to a $0.99 \%$ increase in the average fire occurrence rate in China. As the future climate will be drier, this will present further challenges and put pressure on preventing and reducing fire accidents. Society must pay close attention to the effect of drier climates on fire situations and increase the safety investment in preventing conflagrations.

The urban fire situation in China experiences significant spatial effects, which may be referred to as "fire assimilation effects", "fire inertia effects" and "fire caution effects". With the fire assimilation effect, the improvement or deterioration of a fire situation in a surrounding area will bring about an improvement or deterioration of a fire situation in a local area. The fire inertia effect demonstrates that regions where fire accidents occur frequently previously are most likely to suffer from fire accidents in the future. Regions where the fire situation is improved early on will continue to improve in the future. With the fire caution effect, previous fires that occurred in adjoining areas will have a cautionary effect on the local area and reduce the fire rate in those areas. Fire safety administration departments should take full advantage of these effects and take active measures to improve fire situations.

This paper also has some shortcuts. Considering the data availability and the objective of microanalysis of fire change, this paper only included GDP per capita as the representative indicator of economic development. However, macroeconomic factors such as the economic system, industry structure, education level and income level may also have an influence on the frequency of urban fires. Further research should continue to analyze the influence of the aforementioned factors so that research-led policy may be adopted by government. Otherwise, the degree of spatial autocorrelation of variables depends on the size of spatial particles and zone design methods. However, there is no determined function relationship between the change of spatial units and the autocorrelation. So, how to choose the appropriate size of geographical unit particles and zone design are very important in the research of spatial autocorrelation [49]. It should be studied further.

\section{Acknowledgments}

This study was primarily funded by a grant from the State Key Program of National Natural Science Foundation of China (71433068). Support was also provided by the National Natural Science Foundation of China (41371177), and the National Natural Youth Science Foundation of China (41201168). 


\section{Author Contributions}

Zhenbo Wang conceived and designed the research; Bo Xu performed the data collection; Zhenbo Wang and Xiaorui Zhang analyzed the data and wrote the paper; Bo Xu reviewed the paper and made several comments and suggestions for revision.

\section{Conflicts of Interest}

The authors declare no conflict of interest.

\section{References}

1. Turco, M.; Llasat, M.C.; von Hardenberg, J.; Provenzale, A. Impact of climate variability on summer fires in a Mediterranean environment (northeastern Iberian Peninsula). Clim. Change 2013, 116, 665-678.

2. Moritz, M.A.; Morais, M.E.; Summerell, L.A.; Carlson, J.M.; Doyle, J. Wildfires, complexity, and highly optimized tolerance. Proc. Natl. Acad. Sci. USA 2005, 102, 17912-17917.

3. Wang, X.L.; Thompson, D.K.; Marshall, G.A.; Tymstra, C.; Carr, R.; Flannigan, M.D. Increasing frequency of extreme fire weather in Canada with climate change. Clim. Change 2015, 130, 573-586.

4. Bonan, G.B. Forests and climate change: Forcings, feedbacks, and the climate benefits of forests. Science 2008, 320, 1444-1449.

5. Pyne, S.; Andrews, P.; Laven, R. Introduction to Wildland Fire; Wiley: New York, NY, USA, 1996.

6. Díaz, D.R.; Lloret, F.; Pons, X. Spatial patterns of fire occurrence in Catalonia Landsc. Ecol. 2004, 19, 731-745.

7. Marlon, J.R.; Bartlein, P.J.; Carcaillet, C.; Gavin, D.G.; Harrison, S.P.; Higuera, P.E; Joos, F.; Power, M.J.; Prentice, I.C. Climate and human influences on global biomass burning over the past two millennia. Nat. Geosci. 2008, 1, 697-702.

8. Pausas, J.G.; Keeley, J.E. A burning story: The role of fire in the history of life. Bioscience 2009, 59, 593-601.

9. Oliveras, I.; Gracia, M.; Moré, G.; Retana, J. Factors influencing the pattern of fire severities in a large wildfire under extreme meteorological conditions in the Mediterranean basin. Int. J. Wildland Fire 2009, 18, 755-764.

10. Venevsky, S.; Thonicke, K.; Sitch, S.; Cramer, W. Simulating fire regimes in human-dominated ecosystems: Iberian Peninsula case study. Glob. Chang. Biol. 2002, 8, 984-998.

11. Bowman, D.M.J.S.; Balch, J.K.; Artaxo P.; Bond, W.J.; Carlson, J.M.; Cochrane, M.A.; D'Antonio, C.M.; DeFries, R.S.; Doyle, J.C.; Harrison, S.P. Fire in the earth system. Science 2009, 324, 481-484.

12. Perez, V.G.; Marquez, L.M.A.; Cortes, O.A.; Salmeron, M.M. Spatial-temporal analysis of fire occurrence in Durango. Madera Y Bosques 2013, 19, 37-58.

13. Falk, D.A.; Heyerdahl, E.K.; Brown, P.M.; Farris, C.; Fule, P.Z.; Mckenzie, D.; Swetnam, T.W.; Taylor, A.H.; van Horne, M.L. Multi-scale controls of historical forest-fire regimes: New insights from fire-scar networks. Front. Ecol. Environ. 2011, 9, 446-454. 
14. Liu, Z.H.; Yang, J.; Chang, Y.; Weisberg, P.J.; He, H.S. Spatial patterns and drivers of fire occurrence and its future trend under climate change in a boreal forest of Northeast China. Global. Chang Bio. 2012, 18, 2041-2056.

15. Wang, Z.; Fang, C.; Zhang, X. Spatial expansion and potential zoning of construction land use in the Yangtze River Delta. J. Geogr. Sci. 2015, 25, 1-14.

16. Fang, C.; Wang Z. Quantitative Diagnoses and Comprehensive Evaluations of the Rationality of Chinese Urban Development Patterns. Sustainability 2015, 7, 3859-3884.

17. Syphard, A.D.; Radeloff, V.C.; Keeley, J.E.; Hawbaker, T.J.; Clayton, M.K.; Stewart S.I.; Hammer R.B. Human influence on California fire regimes. Ecol. Appl. 2007, 17, 1388-1402.

18. Yang, J.; He, H.S.; Shifley S.R. Spatial controls of occurrence and spread of wildfires in the Missouri Ozark highlands. Ecol. Appl. 2008, 18, 1212-1225.

19. Duncanson, M.; Woodward, A. Reid, P. Socioeconomic deprivation and fatal unintentional domestic fire incidents in New Zealand. Fire Saf. J. 2002, 37, 165-179.

20. AFAC. Accidental Fire Fatalities in Residential Structures: Who's at Risk? Technical Report; Australian Fire Authorities Council: Canberra, Australia, 2005.

21. Smith, R.; Wright, M.; Solanki, A. Analysis of Fire and Rescue Service Performance and Outcomes with Reference to Population Socio-Demographics-Fire Research Series 9/2008; Department for Communities and Local Government: London, UK, 2008.

22. Yang, L.Z.; Jiang, D.B. The relationship between fire and socioeconomic factors in China. Eng. Sci. 2003, 5, 62-67.

23. Schwartz, N.B.; Uriarte, M.; Gutiérrez V.V.H.; Baethgen, W.; DeFries, R.; Fernandes, K.; Pinedo, V.M.A. Climate, landowner residency, and land cover predict local scale fire activity in the Western Amazon. Global Environ. Change 2015, 31, 144-153.

24. Westerling, A.L.; Turner, M.G.; Smithwick, E.A.H.; Romme, W.H.; Ryan, M.G. Continued warming could transform Greater Yellowstone fire regimes by mid-21st century. Proc. Natl. Acad. Sci. USA 2011, 108, 13165-13170.

25. Scholze, M.W.; Knorr, N.W.; Arnell, N.W.; Prentice, I.C. A climate-change risk analysis for world ecosystems. Proc. Natl. Acad. Sci. USA 2006, 103, 13116-13120.

26. Chrysoulakis, N.; Cartalis, C. Thermal detection of plumes produced by industrial accidents in urban areas based on the presence of the heat island. Int. J. Rem. Sens. 2002, 23, 2909-2916.

27. Panao, M.J.N.O.; Goncalves, H.J.P.; Ferrao, P.M.C. Optimization of the urban building efficiency potential for midlatitude climates using a genetic algorithm approach. Renew. Energ. 2008, 33, 887-896.

28. Corcoran, J.; Higgs, G.; Rohde, D. Investigating the association between weather conditions, calendar events and socio-economic patterns with trends in fire incidence: An Australian case study. J. Geogr. Syst. 2011, 13, 193-226.

29. Gunther, P. Rural fire deaths: the role of climate and poverty. Fire J. 1982, 76, 34-39.

30. Sufianto, H.; Green, A.R. Urban fire situation in Indonesia. Fire Tech. 2011, 2, 357-387.

31. Standardization Administration of the People's Republic of China. Urban Fire-Danger Weather Ratings GB/T 20487-2006; China Standards Publishing House: Beijing, China, 2006.

32. Langner, A.; Siegert F. Spatiotemporal fire occurrence in Borneo over a period of 10 years. Glob. Change Biol. 2009, 15, 48-62. 
33. Frejaville, T.; Curt, T. Spatiotemporal patterns of changes in fire regime and climate: Defining the pyroclimates of south-eastern France (Mediterranean Basin). Clim. Change 2015, 129, 239-251.

34. Zhang, J.Q.; Liu, X.P.; Tong, Z.J. The study of grassland fire disaster risk assessment and regionalization: A case study in the western Jilin Province. Geogr. Res. 2007, 26, 755-762.

35. Yan, F.; Ang, Y.J.; Wu, B. Spatial and temporal distributions of drought in Hebei Province over the past 50 years. Geogr. Res. 2010, 29, 423-430.

36. Jennings, C.R. Socioeconomic characteristics and their relationship to fire incidence: A review of the literature. Fire Tech. 1999, 35, 7-34.

37. Chang, H.S. Study of the exploration of fire occurrence spatial characteristics and impact factors: a case study of Tainan City. In Proceedings of 14th International Conference on Urban Planning and Regional Development in the Information Society, Spain, 22-25 April 2009; Design Center Sitges: Sitges, Spain, 2009.

38. Tobler, W.A. A computer movie simulating urban growth in the Detroit region. Econ. Geogr. 1970, 46, 234-240.

39. Houthakker, H.S. The Pareto Distribution and the Cobb-Douglas Production Function in Activity Analysis. Rev. Econ. Stud. 1955, 23, 27-31.

40. Gao, T.M. Econometric Methods and Modeling; Tsinghua Publishing House: Beijing, China, 2009.

41. Zhang, Z.-Y.; Zhu, P.F. Improvement on asymptotic efficiency of QMLE for SDPD model. J. Quant. Tech. Econ. 2009, 5, 145-157.

42. Anselin, L.; Griffith, D.A. Do spatial effects really matter in regression analysis? Pap. Reg. Sci. Assoc. 1988, 65, 11-34.

43. Legendre, P. Spatial autocorrelation: trouble or new paradigm? Ecology 1993, 74, 1659-1673.

44. Osborne, P.E.; Foody, G.M.; Suarez-Seoane, S. Non-stationarity and local approaches to modelling the distributions of wildlife. Divers. Distrib. 2007, 13, 313-323.

45. Liang, W.; Ren, B.P. Judgment of China's Economic Development Stages and the Analysis of the Characters at the Current Economic Development Stage. J. Quant. Tech. Econ. 2009, 4, 3-18.

46. Ding, Y.H.; Ren, G.Y.; Shi, G.Y. National assessment report of climate change (I): Climate change in China and its future trend. Adv. Clim. Change Res. 2006, 2, 3-8.

47. Xu, Y.L.; Huang, X.Y.; Zhang, Y. Statistical analyses of climate change scenarios over China in the 21 st Century. Adv. Clim. Change Res. 2005, 1, 80-83.

48. Xu, B.; He, N.; Gong, P.; Li, Y. Spatiotemporal evolution characteristics of fire disasters in China: GIS-based statistic analysis. J. Nat. Disasters 2012, 21, 198-203.

49. Openshaw, S. The Modifiable Areal Unit Problem; Geo Books: Norwick, UK, 1983.

(C) 2015 by the authors; licensee MDPI, Basel, Switzerland. This article is an open access article distributed under the terms and conditions of the Creative Commons Attribution license (http://creativecommons.org/licenses/by/4.0/). 